\title{
Intact cross-talk between insulin secretion and insulin action after postgastroplasty recovery of ideal body weight in severely obese patients
}

\author{
MR Letiexhe ${ }^{1}$, C Desaive ${ }^{2}$, PJ Lefèbvre ${ }^{1}$ and AJ Scheen ${ }^{1}$ \\ ${ }^{1}$ Division of Diabetes, Nutrition and Metabolic Disorders, Department of Medicine, CHU Sart Tilman, Liège, Belgium; and ${ }^{2}$ Department of \\ surgery, CHU Sart Tilman, Liège, Belgium
}

\begin{abstract}
Most reports investigating the hormonal and metabolic effects of bariatric surgery studied obese subjects after partial weight loss only. Nevertheless, all studies showed significant improvements of insulin secretion, action, clearance and inhibition of its own secretion, although the parallel kinetics of all these changes remained questionable. Using the intravenous glucose tolerance test, we demonstrated a full normalization of insulin secretion, action on glucose metabolism and clearance in eight obese women who recovered and maintained ideal body weight following gastroplasty. Reciprocal changes were observed between postglucose acute insulin secretion and insulin-mediated glucose disposal so that the so-called disposition index (product of these two variables) remained unchanged after $v$ s before gastroplasty in those individuals with normal glucose tolerance. These favourable results should encourage obtaining a drastic and sustained weight loss in patients with severe obesity at risk of developing type II diabetes.
\end{abstract}

Keywords: gastroplasty; disposition index; insulin secretion; insulin sensitivity; intravenous glucose tolerance test

Obesity is rapidly growing in all countries, especially its massive form in the United States. ${ }^{1}$ Numerous epidemiological ${ }^{1}$ and clinical studies ${ }^{2}$ have demonstrated that obesity is strongly and causally linked to impaired glucose metabolism and type II diabetes. Weight management has the potential to make a significant impact in subjects with established type II diabetes, and recent data suggest that prevention of diabetes is feasible if weight management is addressed adequately in individuals at high risk. ${ }^{3}$ Hyperinsulinaemia is a key feature of obese subjects. Such high circulating insulin levels may result from various mechanisms, that is, increased insulin secretion (at least partially as a compensatory mechanism in face of insulin resistance) and decreased insulin clearance (presumably due to a reduced hepatic insulin extraction). ${ }^{4}$ Pereira $e t a l^{5}$ recently reported in the Journal that insulin inhibition on its own secretion was blunted in insulin-resistant severely obese patients, partially related to the degree of obesity, a phenomenon that may contribute to aggravate hyperinsulinaemia. In addition, they demonstrated that postsurgery (either vertical banded gastroplasty or gastric bypass) weight loss completely normalized the insulin effect on its own secretion, despite the persistence of moderate obesity, while it only partially improved insulin-induced glucose uptake.

In a previous study, Pereira $e t a l^{5}$ showed that insulin infusion under euglycaemic conditions at steady state inhibits its own secretion in lean subjects but that this insulin action is blunted in the obese group. ${ }^{6}$ By contrast, our group reported a normal feedback inhibition of insulin secretion by insulin in moderately obese subjects, contrasting with a markedly reduced metabolic clearance rate of the hormone, a factor that may contribute to hyperinsulinaemia. ${ }^{7}$ However, obese subjects evaluated by our group had a less extreme obesity as compared to those tested by Pereira et al (BMI: $33.0 v s 54.6 \mathrm{~kg} / \mathrm{m}^{2}$ ), a difference that may suggest that blunted inhibition of insulin on its own secretion is only present in morbidly obese subjects. A further argument in favour of such a conclusion is the observation of Pereira $e t a l^{5}$ that the insulin inhibitory effect on its secretion is fully restored after partial weight loss despite the persistence of elevated body weight. Apparently, the improvement of this inhibitory effect of insulin on its own secretion after gastroplasty or gastric bypass was not clearly related to the degree of weight loss as it appeared more pronounced at 4 months (when BMI decreased from 54.6 to 44.5 $\mathrm{kg} / \mathrm{m}^{2}$ ) than at 14 months (when BMI further decreased to $33.9 \mathrm{~kg} / \mathrm{m}^{2}$ ). The results of Pereira $e t a l^{5}$ suggested a partial dissociation between an apparently full normalization of insulin inhibition on insulin secretion (no more insulin resistance at the B-cell level, a mechanism that may contribute to modulate insulin secretion) and a persistent decrease in insulin-mediated glucose disposal (still insulin resistance at the muscle site) after weight reduction. A dissociation between changes in insulin secretion and insulin sensitivity has already been reported during the course of drastic weight loss after bariatric surgery with, however, a restoration of insulin sensitivity 
preceding that of insulin secretion. ${ }^{8}$ In a previous study, we reported partial but comparable postweight loss improvement of insulin secretion and insulin sensitivity in 12 severely obese subjects who still remained overweight after bariatric surgery (BMI reduction from 37.9 to $26.5 \mathrm{~kg} / \mathrm{m}^{2}$ ). ${ }^{9}$

None of these studies investigated these hormonal and metabolic parameters in individuals who recovered ideal body weight. Fortunately, we had the opportunity to evaluate eight obese women after recovery and stabilization of ideal body weight 14 months after a successful vertical banded gastroplasty (reduction of BMI from 37.7 to $\left.23.7 \mathrm{~kg} / \mathrm{m}^{2}\right) .{ }^{10}$ In those subjects, we demonstrated a full normalization of insulin secretion, action on glucose metabolism and clearance. These results were obtained during a frequently sampled intravenous glucose tolerance test using the minimal model approach to assess insulin sensitivity and the deconvolution of plasma C-peptide levels to assess insulin secretion kinetics. This technique does not allow studying the insulin inhibition on insulin secretion and thus we cannot compare our data with those of Pereira $e a^{5} l^{5}$ in this respect. However, the intravenous glucose tolerance test allows a careful evaluation of the intimate relationship between acute insulin response (AIR) to glucose and insulin sensitivity as previously described. ${ }^{11}$ The importance of the socalled disposition index (AIR x insulin sensitivity) has been recently emphasized and illustrated in various clinical conditions. ${ }^{12,13}$ Figure 1 illustrates the reciprocal changes in AIR and insulin sensitivity index after $v s$ before weight loss in the above-mentioned eight obese women with normal glucose tolerance who succeeded in normalizing BMI after gastroplasty ${ }^{14}$ The cross-talk between insulin secretion and insulin sensitivity is illustrated by the rightward and downward shift of the dots from 'before gastroplasty' to 'after gastroplasty' along the hyperbolic curve linking AIR and insulin sensitivity observed in a large cohort of 109 subjects with variable BMI but normal glucose tolerance during an oral glucose tolerance test. Thus, the disposition index remained almost unchanged in postobese subjects evaluated after gastroplasty as compared to the values calculated before gastroplasty when severe obesity was present (45433 \pm 9284 vs $36407 \pm 636910^{-5} \mathrm{l}_{\mathrm{min}} \mathrm{m}^{-1} P=0.387$, NS). However, fasting and postload glucose concentrations were slightly increased in severely obese subjects with decreasing insulin sensitivity despite normal compensation of AIR, as compared to lean and postobese subjects. ${ }^{10}$ Changes along the hyperbola, with disposition index remaining constant, are consistent with the hypothesis that glucose is a signal that stimulates AIR to compensate for insulin resistance, a concept recently called 'glucose allostasis'. $^{13}$

Figure 1: Hyperbolic relationship between acute insulin response to glucose $\left(A I R_{G O-10 m i n}\right)$ and insulin sensitivity $\left(S_{I}\right)$ measured during a frequently sampled intravenous glucose tolerance test. The curve was derived from the results obtained in a personal series of 109 subjects with variable BMI but normal glucose tolerance. Changes after (postobese) vs before (obese) gastroplasty are illustrated in eight obese women who recovered ideal body weight after bariatric surgery (mean \pm s.e.m.).

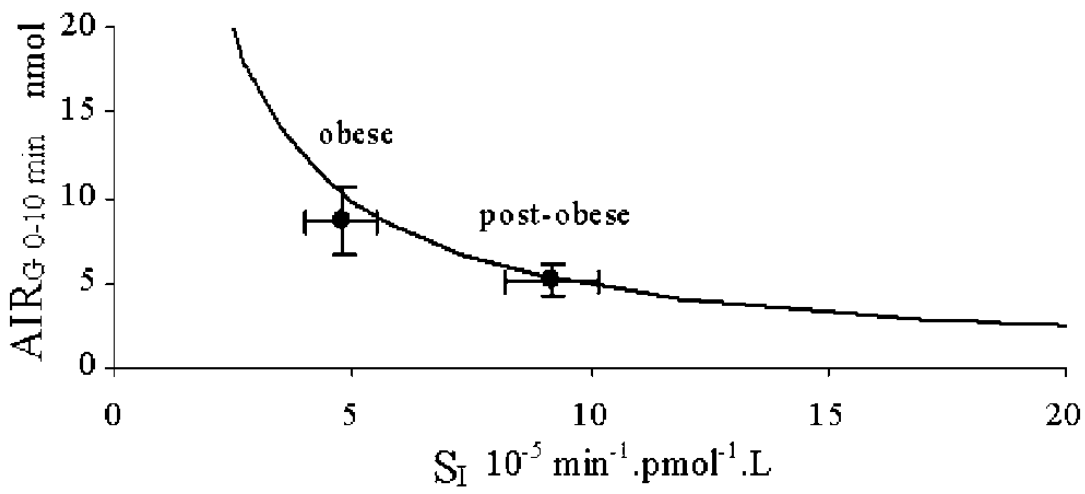

In conclusion, postgastroplasty recovery of ideal body weight in severely obese subjects results in a full normalization of all indices of insulin secretion, action and clearance, the so-called 'disposition index' remaining constant. Such results represent a further argument for obtaining and maintaining a drastic weight loss in patients with extreme obesity at high risk of developing type II diabetes. They may explain why the incidence of type II diabetes is drastically decreased in obese patients submitted to bariatric surgery as demonstrated after 2 and 8 years of follow-up in the prospective Swedish Obese Subjects study ${ }^{15}$ 


\section{References}

1 Mokdad AH, Bowman BA, Ford ES, Vinicor F, Marks JS, Koplan JP. The continuing epidemics of obesity and diabetes in the United States. JAMA 2001; 286: 1195-2000.

2 Scheen AJ, Paquot N, Letiexhe M, Paolisso G, Castillo MJ, Lefèbvre PJ. Glucose metabolism in obese subjects: lessons from OGTT, IVGTT, and clamp studies. Int J Obes Relat Metab Disord 1995; 19 (Suppl): S14-S20.

3 Scheen AJ. Current management strategies for coexisting diabetes mellitus and obesity. Drugs 2003; 63: $1165-1184$.

4 Castillo MJ, Scheen AJ, Jandrain B, Lefèbvre PJ. Relationships between metabolic clearance rate of insulin and body mass index in a female population ranging from anorexia nervosa to severe obesity. Int f Obes Relat Metab Disord 1994; 18 : 47-53.

5 Pereira JA, Claro BM, Pareja JC, Chaim EA, Astiarraga BD, Saad MJA, Muscelli E. Restored insulin inhibition on insulin secretion in nondiabetic severely obese patients after weight loss induced by bariatric surgery. Int f Obes Relat Metab Disord 2003; 27: $463-468$.

6 Muscelli E, Pereira JA, Lazarin MACT, Silva CA, Pareja JC, Saad MJA. Lack of insulin inhibition on insulin secretion in nondiabetic morbidly obese patients, Int f Obes Relat Metab Disord 2001; 25: 798-804.

7 Scheen A, Castillo M, Paolisso G, Jandrain B, Lefèbvre PJ. Normal feedback inhibition of insulin secretion by insulin but reduced metabolic clearance rate of the hormone in obese subjects. In: Ailhaud G, Guy-Grand B, Lafontaine M, Ricquier D (eds). Obesity in Europe 91. John Libbey \& Co.: London; 1992. pp 201-205.

8 Jimenez J, Zuniga-Guajardo S, Zinman B, Angel A. Effects of weight loss in massive obesity on insulin and C-peptide dynamics: sequential changes in insulin production, clearance, and sensitivity, f Clin Endocrinol Metab 1987; 64: 661-668.

9 Letiexhe MR, Scheen AJ, Gérard PL, Desaive C, Lefèbvre PJ. Insulin secretion, clearance and action before and after gastroplasty in severely obese subjects, hit f Obes Relat Metab Disord 1994; 18: 295-300.

10 Letiexhe MR, Scheen AJ, Gérard PL, Desaive C, Lefèbvre PJ. Post-gastroplasty recovery of ideal body weight normalizes glucose and insulin metabolism in obese women, f Clin Endocrinol Metab 1995; 80: 364-369.

11 Kahn SE, Prigeon RL, McCulloch DK, Boyko EJ, Bergman RN, Schwartz MW, Neifin JL, Ward WK, Beard JC, Palmer JP, Porte D. Quantification of the relationship between insulin sensitivity and $\beta$-cell function in human subjects. Diabetes 1993; 42: $1663-1672$.

12 Bergman RN, Ader M, Huecking K, Van Citters G. Accurate assessment of $\beta$-cell function. Diabetes $2002 ; 51$ (Suppl 1): S212-S220.

13 Stumvoll M, Tataranni A, Stefan N, Vozarova B, Bogardus C. Persectives in diabetes. Glucose Allostasis. Diabetes 2003; 52: 903-909.

14 Letiexhe MR, Scheen AJ, Desaive C, Lefèbvre PJ. Hyperbolic relationship between changes in insulin secretion and action in obese subjects after gastroplasty (Abstract). Diabetologia 1995; 38 (Suppl 1): A158.

15 Sjöström CD, Peltonen M, Wedel H, Sjöström L. Differentiated long-term effects of intentional weight loss on diabetes and hypertension. Hypertension 2000; 36: 20-25. 